\title{
Os projetos político-pedagógicos dos cursos de pedagogia e os temas ambientais: o caso das universidades federais brasileiras
}

\author{
Maíra Gesualdo Oliveira* \\ Luiz Marcelo de Carvalho*
}

\section{Resumo}

A discussão em torno da temática ambiental e das possibilidades e limites do processo educativo relacionado com as questóes propostas por essa temática se faz presente em muitos setores da sociedade atual. A produção e veiculação de pesquisas e a proposiçáo de programas e açóes relacionados principalmente com a inserção da Educação Ambiental (EA) no ensino formal nos permitem vislumbrar a amplitude que tal iniciativa vem tomando. Nesse contexto, desenvolvemos uma pesquisa em nível de mestrado que se insere no âmbito do Projeto Observatório da Educação Capes/INEP/Secadi e procura analisar possíveis processos de ambientalização curricular expressos nos projetos políticopedagógicos (PPP) dos cursos de licenciatura em Pedagogia de universidades federais brasileiras. $\mathrm{O}$ artigo que apresentamos é um recorte dessa pesquisa no qual aprofundamos a discussão de dois temas ambientais: - As dimensóes da EA - e - Desenvolvimento e natureza: algumas possibilidades -. Assim, partindo de uma pesquisa documental e tendo o apoio teórico de autores que têm procurado refletir sobre os significados da temática ambiental para as sociedades contemporâneas e sobre propostas críticas para a Educação Ambiental, procura-se explorar, por meio de análise dos PPPs, possíveis sentidos atribuídos a esses processos de ambientalização curricular. Como principal referencial metodológico, nos apoiamos na proposta de - produção de sentidos - apresentada por Gomes e Nascimento (2006). Algumas reflexôes sobre os dados nos permitem vislumbrar que diferentes temas ambientais vêm sendo considerados nos projetos desses cursos, o que evidencia movimentos e processos de ambientalização curricular.

Palavras-chave: Educação Ambiental. Formação de professores. Educação Superior.

* Mestre em Educação pela Universidade Estadual Paulista Júlio de Mesquita Filho (UNESP).

** Doutor em Educaçáo pela Universidade de São Paulo (USP). Professor do Departamento de Educação da Universidade Estadual Paulista Júlio de Mesquita Filho (UNESP). 


\section{Introdução}

A questão ambiental emerge como problema significativo em nível mundial a partir das décadas de 1960 e 1970, devido à constatação, pelas sociedades ocidentais, do quadro de degradação ambiental que se apresentava ao público, principalmente por meio da publicaçáo de relatos de acidentes envolvendo riscos, e danos ambientais e sociais potenciais e concretos. São propostas, entáo, inúmeras conferências e encontros que procuram discutir a temática e encontrar soluçôes para os problemas que começavam a anunciar uma crise ambiental que afetaria significativamente os ecossistemas, com prejuízos, inclusive, para a população humana. Tais debates, presentes em diferentes esferas da sociedade, ganham um enfoque mais crítico, principalmente na década de 1970, quando se somam a outros fomentados pelos movimentos sociais de natureza diversa. Esses movimentos contestavam, sobretudo, o sistema de produçáo capitalista, baseado na lógica de mercado e que caracteriza a grande maioria das sociedades ocidentais. Segundo Carvalho (2001), é nesse momento que começa a configurarse de forma mais sistemática um conjunto de açóes e movimentos sociais que se intitulam inicialmente - ecológicos - e posteriormente - ambientais - e, no plano governamental, a proposição de estruturas institucionais voltadas ao controle e organização das questóes ambientais.

Em confluência com as discussôes relacionadas à temática ambiental que se articulavam em diferentes países do mundo ocidental e oriental, surgem as primeiras proposiçôes que enfatizam o processo educativo como um possível caminho, quando não o único caminho possível, para a superação da crise ambiental. Nesse contexto, a Educação Ambiental (EA) emerge como um campo de grande significado nas propostas de uma educação voltada para a qualidade dos ambientes e o bem-estar da sociedade.

Entendida como uma área do conhecimento que envolve uma multiplicidade de conceitos e possui uma fundamentação epistemológica que se apoia tanto no campo das Ciências Humanas como no das Ciências Naturais, a EA vem se consolidando como um campo de pesquisas e açóes voltadas para o entendimento integral da referida crise ambiental. Buscam-se, ainda, com as açóes educacionais, propostas de intervençóes que possam alterar o quadro de degradação socioambiental com o qual nos deparamos nos tempos atuais. A Conferência de Estocolmo (1972) representa um marco para as discussóes quanto ao papel do processo educativo relacionado com a temática ambiental. 
$\mathrm{Na}$ experiência brasileira, a introdução e a institucionalização da EA na sociedade passam pela articulação de açôes e políticas que objetivam inserir a abordagem e a discussão da temática ambiental no processo educativo formal e informal. Para o Ensino Superior formal, principalmente para os cursos que formam professores, é possível constatar sugestóes de inserção em algumas políticas públicas voltadas para a temática ambiental e também para a educação. A Política Nacional de Educação Ambiental (PNEA), Lei no 9.795/99 (BRASIL, 1999), aprovada em 1999, considera a EA um componente essencial e permanente da educação nacional em todos os níveis e modalidades do processo educativo. O Sistema Nacional de Avaliação da Educação Superior (Sinaes) inclui entre suas dimensôes para avaliação a responsabilidade da instituiçáo no que tange à defesa do meio ambiente (Artigo 3ํ, III) (BRASIL, 2004). Além dos textos legais, há o ProNEA (Programa Nacional de Educação Ambiental) (BRASIL, 2005), com a indicação de que a EA deve estar presente no âmbito da Educação Superior Outra política importante relacionada à formação de professores para as séries iniciais são as Diretrizes Curriculares Nacionais para os Cursos de Pedagogia (DCN Pedagogia) (BRASIL, 2006), que incluem entre as suas indicações a abordagem da temática no referido curso. Tal sugestão parece se relacionar com a proposição dos Parâmetros Curriculares Nacionais (PCN) (BRASIL, 1998) de se abordar o tema "Meio Ambiente" de forma transversal na Escola Básica, na qual tais professores atuarão.

Percebe-se que há uma tendência, também presente nos cursos que formam professores, que aponta processos de ambientalização curricular no Ensino Superior em diversas áreas de formação. Segundo Junyent, Geli e Arbat (2003, p. 29), o processo de ambientalização curricular no Ensino Superior consiste na:

Incorporação pelos cursos de graduação e pós[-]graduação das Unidades Universitárias de diferentes dimensóes que são hoje trazidas pelo movimento ambientalista e por outros agentes sociais e que estáo diretamente relacionadas com a temática ambiental. (JUNYENT; GELI; ARBAT, 2003, p. 29, grifo nosso).

Entendemos que a incorporação da temática ambiental nos currículos pode ser compreendida quando se considera a expressão do currículo como 
"cultura" (MOREIRA; MACEDO, 2002), visto que o campo ambiental pode ser interpretado, hoje, como um campo de disputa simbólica (por conhecimentos selecionados, significados, validação de grupos) que envolve muitas esferas da sociedade.

Alguns estudos sobre a inserção da temática no Ensino Superior vêm sendo desenvolvidos. Um estudo importante foi o "Mapeamento da Educação Ambiental em instituiçóes brasileiras de Educação Superior: elementos para políticas públicas" (RUPEA, 2007), que tinha entre seus principais objetivos servir de subsídio às ações governamentais de implementação da PNEA no que diz respeito ao nível de Ensino Superior.

Outras pesquisas (FARIAS, 2008; GONZALEZ, 2008; PAVESI, 2007) consideram que há uma tendência para a abordagem da dimensão ambiental nesse nível de ensino, porém, apesar de as diretrizes curriculares para o Ensino Superior sugerirem essa inserção, as universidades possuem autonomia na elaboração dos seus currículos, podendo ou não atender a tal indicação. Em relaçáo aos estudos sobre os cursos de Pedagogia que formam professores que atuarão nas séries iniciais do Ensino Fundamental, já se observam algumas investigações na forma de estudos de caso. Um exemplo desse tipo de trabalho é a pesquisa intitulada "Ambientalização curricular na formação inicial de professores: o curso de Pedagogia da FE-Unicamp" (ROSALEN; BAROLLI, 2009).

Diante desse contexto de inserção da temática ambiental no Ensino Superior e interessados principalmente naqueles cursos que formam professores para a Educação Infantil e para as séries iniciais do Ensino Básico, apresentamos neste artigo algumas análises constantes de uma pesquisa que faz parte do Programa Observatório da Educação Capes/MEC. Essa pesquisa procura identificar, analisar e compreender processos de ambientalização curricular dos cursos de Pedagogia de universidades federais brasileiras. Neste artigo, nos detemos em dois dos quatro temas ambientais encontrados nos projetos político-pedagógicos (PPPs) dos referidos cursos. O PPP é uma importante esfera do currículo, uma vez que explicita os posicionamentos e intençóes relativos à educação e a determinado curso. 


\section{Metodologia}

A pesquisa que deu origem a este trabalho teve por base uma abordagem qualitativa e se caracterizou como documental. Nela são analisados documentos elaborados pelas universidades federais brasileiras que se referem a projetos político-pedagógicos de cursos Pedagogia.

O procedimento escolhido para a produção e análise dos dados foi uma "[...] adaptação da técnica de análise de conteúdo, modalidade temática, descrita por Bardin” (GOMES; NASCIMENTO, 2006, p. 903). Bardin (2004, p. 27) afirma que "[...] a análise de conteúdo é um conjunto de técnicas de análise das comunicaçōes", sendo "comunicaçōes" tudo aquilo que é dito ou escrito entre um emissor e um receptor. O objetivo da análise de conteúdo é interpretar essas comunicações revelando seus sentidos. A modalidade "análise temática" busca núcleos de sentido na comunicação. Segundo Gomes e Nascimento (2006), na modalidade temática da análise de conteúdo, proposta por Bardin (2004, p. 105), o tema "[...] é uma unidade de significação que se liberta do texto analisado e pode ser traduzido por um resumo, uma frase ou uma palavra". $\mathrm{Na}$ busca dos temas, se faz necessário "[...] descobrir os núcleos de sentidos que compóe $[\mathrm{m}]$ a comunicação e cuja presença ou freqüência de aparição pode significar alguma coisa para o objetivo analítico escolhido" (BARDIN, 2004, p. 105). Gomes e Nascimento (2006) alertam que, na análise temática de Bardin, o núcleo de sentido é ponto de partida para se estabelecerem os temas, sendo o núcleo e o tema integrantes do mesmo processo. Na proposta de Gomes e Nascimento (2006), o tema é entendido como uma categoria mais ampla, podendo abranger mais de um núcleo de sentido. Os núcleos de sentido, por sua vez, são constituídos de unidades de significado, sendo essas unidades expressóes na forma de frases ou textos presentes nos documentos analisados. Sendo assim, na análise dos documentos e projetos político-pedagógicos, caminhou-se na identificação das unidades de significado e, a partir delas, das ideias centrais, passando-se pela construção de possíveis sentidos dessas ideias e o agrupamento delas em categorias empíricas ou núcleos de sentido, chegandose, enfim, à descrição dos temas como classificaçôes mais amplas.

Na busca do entendimento do conceito de "sentido" e "significado", nos aproximamos do referencial proposto por Mikhail Bakhtin (18951975). Bakhtin (1988) aponta que o entendimento do mundo se dá por meio dos signos, não sendo possível compreender o homem, sua vida, seu 
trabalho, suas lutas senão por meio de signos criados ou por criar. A ação física do homem precisa ser compreendida como um ato, porém, esse ato não pode ser compreendido fora de sua expressão sígnica, que é por nós recriada (FREITAS, 2002). Considerando essa perspectiva, entendemos que a criação e a interpretação dos dados são determinadas pela relação entre pesquisador e objeto de pesquisa. Freitas (2002) afirma que o pesquisador faz parte da própria situação de pesquisa, logo, a neutralidade é impossível, sua açâo e também os efeitos que propicia constituem elementos de análise. Segundo essa autora, Bakhtin, em uma proposta de entender o ato da pesquisa, afirma que:

Náo perguntamos à natureza e a natureza não nos
contesta. Perguntamos a nós mesmos e organizamos de
uma maneira determinada a observação ou o experimento
para obter a resposta. Estudando o homem em todas as
partes buscamos e encontramos signos e tratamos de
compreender seu significado. (BAKHTIN, 1985, p. 305
apud FREITAS, 2002, p. 24).

Freitas (2002) considera que, nas Ciências Humanas, ao se trabalhar com a interpretação das estruturas simbólicas, é necessário ir à infinitude dos sentidos simbólicos. Essa interpretação dos sentidos é profundamente cognoscitiva: "[...] há que se reconhecer que a simbologia não é uma forma não científica do conhecimento, senão uma forma outra do conhecimento que tem suas leis internas e seus critérios de exatidão" (BAKHTIN, 1985, p. 382, apud FREITAS, 2002, p. 24). Para Bakhtin (1988), cada pessoa tem um horizonte social definido e estabelecido que orienta a sua compreensáo e a coloca diante de seu interlocutor com uma forma própria de relacionamento. A partir dessa situação social, do contexto em que se situa, cada um constrói suas deduçôes, motivaçóes e apreciaçóes. A leitura que faz do outro e dos acontecimentos que o cercam está impregnada do lugar de onde fala e orientada pela perspectiva teórica que conduz a investigação (FREITAS, 2002).

Sendo assim, entendemos que a busca pelos significados e sentidos se caracteriza por uma significação e ressignificação dos símbolos expressos nos textos, na relação com o sujeito pesquisador. A busca por sentidos, nessa perspectiva, é a busca por respostas às perguntas que se faz, sendo os sentidos apreendidos as próprias respostas criadas pelo sujeito de pesquisa na sua relação 
com o objeto. O pesquisador, portanto, faz parte da própria situação de pesquisa, de modo que a neutralidade é impossível (FREITAS, 2002).

A análise dos documentos, seguindo a proposta de Gomes e Nascimento (2006), se iniciou com a leitura exaustiva dos textos buscando-se encontrar as unidades de significado e ideias neles presentes. As unidades de significado se caracterizam por excertos literais dos documentos. Posteriormente, essas unidades e ideias foram agrupadas em núcleos de sentido, que expressam ideias entendidas como unidades de significado que se aproximam. Em etapa posterior, esses núcleos de sentido foram agrupados em temas mais abrangentes.

Em síntese, o caminho consistiu nas seguintes etapas: (a) leitura exaustiva de cada PPP com o objetivo de obtermos uma compreensão global de cada documento; (b) identificação das ideias referentes à temática ambiental em cada PPP; (c) tentativas de agrupamento de núcleos de sentido das diferentes ideias referentes à temática ambiental (por exemplo, "desenvolvimento sustentável", "metodologias de ensino em EA", "relaçôes sociedade-natureza"); (d) comparação entre os diferentes núcleos de sentido presentes nos documentos estudados; (e) reunião dos núcleos de sentido em eixos mais abrangentes (temas) em torno dos quais giravam as discussóes dos autores; e (f) redação das sínteses interpretativas de cada tema, considerando a literatura específica sobre Educação Ambiental e sobre formação de professores (GOMES; NASCIMENTO, 2006).

Para a realizaçáo da pesquisa, fizemos, inicialmente, um levantamento dos cursos de Pedagogia oferecidos em universidades federais do País de forma regular e presencial. Identificamos que, das 58 universidades federais existentes no País, até julho de 2010, 48 oferecem cursos de Pedagogia em diferentes campi e turnos. Observamos, também, que em alguns casos os cursos oferecidos por uma mesma universidade, porém, em diferentes campi e turnos, propóem PPPs distintos. Conseguimos coletar projetos de 37 universidades (ainda que não de todos os cursos oferecidos por elas), o que representa $77,1 \%$ das universidades federais que oferecem cursos de Pedagogia. Os dados aqui apresentados se referem a 79 PPPs analisados.

Fica bastante evidente, em nossa análise por meio das unidades de significado identificadas, o quanto questôes relacionadas a diferentes temas ambientais estão presentes nos PPPs. Parece-nos, assim, bastante plausível que essas questóes sejam vistas por nós como pontos valorizados e que assumem espaços significativos nos projetos dos cursos de Pedagogia. 


\section{Projetos Político-Pedagógicos de Cursos de Pedagogia e temas ambientais}

A partir da sistematização e análise das unidades de significado presentes nos PPPs e construção dos núcleos de sentido, pudemos identificar quatro temas ambientais em tais projetos: 1) Dimensóes da EA: conhecimentos, valores e participação política; 2) Relaçóes sociedade-natureza; 3) Desenvolvimento e natureza: algumas possibilidades; 4) Princípios metodológicos relacionados à EA: contextualização, interdisciplinaridade, temas transversais.

Neste trabalho, nos aprofundaremos sobre os temas 1 e 3, o que se justifica pelo fato de que, quando consideramos os possíveis sentidos atribuídos à temática ambiental por nós percebidos, reconhecemos a presença marcante desses temas nos PPPs e certa complementaridade entre eles.

No que diz respeito ao tema Dimensóes da EA: conhecimentos, valores e participaçâa política, percebemos que questốes relacionadas a essas dimensóes apareceram frequentemente nos PPPs aos quais tivemos acesso. Em 53 dos 79 projetos analisados, encontramos unidades de significado que se referem a essas dimensóes.

Para melhor sistematização dos dados, organizamos em três núcleos de sentido as questôes referentes a essas três dimensôes. São eles: Educação Ambiental, meio ambiente e a questäo dos conhecimentos; Questôes valorativas: meio ambiente e EA; Educação Ambiental e a dimensão politica.

O principal referencial em que nos apoiamos para tratar dessas três dimensões foi o de Carvalho (2006). Para esse autor, nas açóes e reflexões sobre EA é importante considerar algumas dimensóes fundamentais da existência humana, quais sejam: a dimensão dos conhecimentos, a dimensão axiológica, que abarca as questóes valorativas éticas e estéticas, e a dimensão da participaçáo política. Por meio de uma espécie de modelo teórico, Carvalho (2006) propóe uma possibilidade de se estabelecerem caminhos tanto para o planejamento de propostas de EA como para a análise de práticas e investigaçóes nesse campo da educaçáo.

Cabe ressaltar que esse modelo não é apontado pelo autor como "seguro" nem como o único caminho nas orientações das propostas em EA, porém, dada a sua perspectiva dialética, permite articular as referidas dimensões. A dimensão política, para o autor, se constitui como central nos processos 
educativos, complementando e sendo complementada pelas outras duas, em uma relação dialética.

Carvalho (2006) acredita que a articulação dessas três dimensóes em uma prática educativa pode abrir caminhos e possibilidades que garantam concretizar as intencionalidades expressas nos PPPs em projetos reais que respondam, de fato, aos objetivos neles propostos.

Assim, a intenção deste texto é aprofundar a discussão sobre dois dos temas enfatizados nos projetos, articulando uma reflexão já acumulada sobre tais temas com algumas propostas presentes nos PPPs.

Em relação à dimensão dos conhecimentos, Carvalho (2006) destaca sua importância na construçáo simbólica da realidade pelos sujeitos. Na proposta do autor, essa dimensão deve ir além dos conhecimentos científicos e daqueles que se apresentam de forma exclusivamente escolarizada. Entendemos que a forma como essa dimensáo vem sendo proposta nos projetos e, na grande maioria dos casos, implementada na prática se distancia de uma articulação com as esferas sociais da natureza desse conhecimento. Tal constatação nos orienta para algumas questôes que discutiremos aqui.

Nos projetos analisados, percebemos a tendência para uma abordagem mais informativa, que considera os conhecimentos produzidos pela atividade científica de forma sistematizada, organizada, ordenada e classificada. Podemos observar que, nos 36 projetos que contemplam essa dimensão, poucas vezes identificamos questóes relacionadas com conhecimentos a partir de perspectivas diferentes dessas mencionadas.

Alguns excertos de ementas das disciplinas evidenciam essa tendência, como, por exemplo:

- "[...] níveis de organização, sistemas biológicos, fatores ambientais e genéticos que afetam a biodiversidade" (FREITAS; GIGLIO, 2010). - Disciplina de Educaçáo, Cultura e Meio Ambiente da Universidade Federal de São Paulo (Unifesp).

" "A natureza e suas diferentes esferas ambientais" (FELÍCIO, 2008) - Disciplina de Geografia I da Universidade Federal de Alfenas (UNIFAL).

Quando consideramos isoladamente os dados dos 15 projetos da Regiāo Sudeste analisados, chama a atençáo o fato de dez fazerem referências 
a abordagens com essas mesmas características, enfatizando aspectos do conhecimento biológico e ecológico nas disciplinas propostas.

Os projetos da Região Norte apresentaram também um número significativo: dez de 19 projetos, com foco em aspectos da legislação e do histórico da EA (oito de dez). O foco em questão nesses projetos já nos parece um passo à frente no tratamento das questôes ambientais na perspectiva da Educação Ambiental, uma vez que associa aspectos sociais quando do tratamento do tema. Porém, nos pareceu que esses aspectos eram listados como conhecimentos a serem apresentados, sem uma abordagem mais crítica das questôes históricas e legislativas associadas à temática e à Educação Ambiental.

Essa perspectiva de abordagem dos conhecimentos pôde ainda ser identificada em seis projetos das universidades da Regiấo Nordeste, dois na Região Sul e um na Região Centro-Oeste. Todas as regióes somam um total de 29 projetos com propostas que apontam essa perspectiva.

Leff (2002) faz uma crítica em relação a essa forma de entendimento e de expressão do conhecimento construído pela humanidade. Para esse autor, essa abordagem advém de uma visão racionalista e utilitarista da natureza e das coisas do mundo, a qual acabou por gerar a crise ambiental com que nos deparamos hoje. $\mathrm{O}$ autor entende que as soluçóes baseadas nesse tipo de construçấo não nos tirariam deste contexto de degradação.

Com base nesse entendimento, Carvalho (2006) propóe que as questóes ambientais devem ser tratadas através da articulação dos conhecimentos historicamente construídos sobre os elementos naturais e as realidades sociais, evidenciando-se a relação dos seres humanos organizados em sociedade com a natureza. Nesse sentido, devem-se evitar as perspectivas fatalistas e reducionistas da questão ambiental (CARVALHO, 2006). O autor ainda aponta que seria recomendável que, nas práticas de Educação Ambiental, não ficássemos limitados à consideração de diferentes conhecimentos científicos e filosóficos sobre a natureza e a cultura através de conceitos sistematizados historicamente, acumulados e aceitos pela comunidade científica; deve-se também instigar a investigaçáo sobre processos de produção dos conhecimentos científicos chamando a atenção para os aspectos de ordem, política econômica e social que determinam a sua construção (CARVALHO, 2006). Tal abordagem nos parece fundamental no entendimento mais aprofundado desses conhecimentos. Outras importantes relaçóes entre arte e ciência no conhecimento da natureza são consideradas de grande importância na abordagem dessa dimensão. 
Poucos projetos fazem indicação de uma abordagem mais integrada da dimensão dos conhecimentos. A maioria coloca o conhecimento construído pela ciência como caminho privilegiado para o estudo da natureza, como podemos perceber nos excertos:

- "A natureza enquanto objeto do conhecimento científico; a observação e a experimentação como métodos fundamentais no estudo da natureza" (CUNHA; BORDAS, s/d) - Disciplina de Ciências Naturais no Ensino Fundamental da Universidade Federal da Bahia (UFBA).

- "A aprendizagem por problemas na procura da compreensão científica das relaçóes natureza-sociedade" (KONZEN, 2007) - Disciplina de Fundamentos e Metodologia do Ensino de Ciências da Universidade Federal do Tocantins (UFT), campus Miracema.

Encontramos nos PPPs de somente duas instituições, ambas da Região Norte (quatro projetos), trechos que possuem uma visão mais crítica do conhecimento construído exclusivamente pela ciência. $\mathrm{O}$ trecho que segue considera que os saberes construídos por meio da ciência estáo vinculados ao processo de produção econômica:

- "Significa compreender que os fatos da natureza e da sociedade se constituem nas fontes de onde emergem todos os ângulos do saber, um deles, a ciência, que se processa nas relações de trabalho estabelecidas para a produção econômica" (DEPARTAMENTO, 2008, p. 20) PPP Universidade Federal de Rondônia (UNIR), campus Rolim de Moura.

Alguns projetos apresentam a proposta do "diálogo de saberes" (LEFF, 2002), explicitando posicionamento positivo em relação aos saberes tradicionais e enfatizando propostas que levam em conta esses saberes. Essa perspectiva pôde ser observada em sete projetos, sendo a maioria deles também da Região Norte:

- " "...] realizar investigação educacional que proporcione conhecimentos sobre a realidade sociocultural, ambiental e modos de vida dos estudantes, no sentido de favorecer a vinculação entre os conteúdos escolares, os saberes e necessidades da vida social dos sujeitos" (COORDENAÇÃO, 2009, p. 7) - PPP Universidade Fereal do Amazonas (UFAM). 
Em relação à dimensão valorativa, percebemos que são comuns nos PPPs dos cursos de Pedagogia analisados referências às perspectivas axiológicas nas reflexôes e discursos sobre a temática ambiental. Essas referências, geralmente, fazem alusão aos valores que os sujeitos atribuem à vida, à natureza, aos seres humanos, entre outros, e apontam a necessidade de se trabalharem tais valores com os indivíduos para se construírem valores éticos e estéticos compatíveis com aqueles universais de bem-estar social e de manutenção das dinâmicas naturais do planeta.

Bonotto (2008) aponta que, atualmente, é difícil trabalhar a partir de valores universais. Parece que o aumento do individualismo e do egoísmo nas sociedades contemporâneas acaba por dificultar o desenvolvimento desses valores, tais como respeito à vida em todas as suas formas, cooperação, solidariedade, etc. Araújo e Aquino (2001) alertam que esse individualismo gera certo "relativismo de valores" que pode ter se tornado "[...] uma vertente do autoritarismo ainda mais violenta, posto que idéias e práticas de exclusão são justificadas e naturalizadas a partir de interesses individuais ou de grupos econômicos e/ou ideologicamente dominantes" (ARAÚJO; AQUINO, 2001, p. 11). Bonotto (2008) acredita que valores universais de igualdade, liberdade e respeito ao próximo e às diferenças, mesmo que não possam ser impostos a todas as culturas, devem permear as açóes dos indivíduos ou, pelo menos, ser considerados como possíveis, principalmente em açóes relacionadas a processos educativos e quando se trata das sociedades ocidentais. Dessa forma, os trabalhos que envolvem EA, ao tratarem de questóes ambientais que afetam a humanidade, devem ser articulados a um conjunto de valores universais que a autora acredita serem expressos no "Tratado de Educação Ambiental para Sociedades Sustentáveis e Responsabilidade Global”, elaborado pela sociedade civil na ocasião da ECO 92 e que embasa práticas de EA. A autora salienta que os princípios expressos nesse documento se aproximam dos valores éticos e estéticos, entendidos como o modo como apreciamos e nos relacionamos com as coisas e, no caso, a natureza (BONOTTO, 2008). Um trabalho que inclua a dimensão axiológica, valorizando aspectos estéticos e éticos, poderia sinalizar a construção de uma nova forma de se estabelecerem as relaçôes homem-natureza. Assim, acreditamos que, juntamente com a dimensão dos conhecimentos e da participação política, o trabalho com valores (éticos e estéticos) constitui um pilar para as propostas de EA. 
Em relação aos PPPs analisados, houve maior destaque dos projetos para a questão valorativa na Regiāo Nordeste. Dos 22 projetos que tratam da temática ambiental na região, 12 tratavam de questôes dessa natureza. $\mathrm{O}$ excerto que segue ilustra essa tendência:

- "Demonstrar consciência da diversidade, respeitando as diferenças de natureza ambiental-ecológica, étnico-racial, de gêneros, faixas geracionais, classes sociais, religiōes, necessidades especiais, escolhas sexuais, entre outras" (COMISSÃO, 2007c, p. 15) - PPP da Universidade Federal de Tocantins (UFT), campus Tocantinópolis.

Consideraçóes como a apresentada nesse excerto são muito comuns nos projetos, e a frase "Respeito às diferenças de natureza ambiental-ecológica" é recorrente nas propostas dos cursos. Contudo, sentimos dificuldades de entender esse conceito, pois quase sempre os PPPs não esclarecem seu entendimento de "ambiente", e ficamos na dúvida se tal conceituação considera ou não as relaçôes ambientais em um sentido mais amplo, que envolva também as relaçôes antrópicas.

Outras passagens indicam conotações diferentes da questão ética em relação à natureza:

- "A aprendizagem por problemas na procura da compreensão científica das relaçóes natureza-sociedade. A questão ética, a criação de valores, atitudes e posturas destas relaçóes" (COMISSÃO, 2007c) - Disciplina de Fundamentos e Metodologia do Ensino de Ciências Naturais da UFT, campus Tocantinópolis.

- "Valorização do cuidado com a natureza e a relação disto com a qualidade de vida humana" (COORDENAÇÁO, 2009, p. 23) - PPP da UFAM.

Outro exemplo:

- "[...] Ética no Consumo. Direitos da Natureza e crise socioambiental [...]” (ARCE; LUIZ, 2008). - Disciplina de Consumo Ético: Humanização Dialógica na Sociedade Contemporânea da Universidade Federal de São Carlos (UFSCar), campus São Carlos.

Outra questão recorrente nos projetos é a associaçâo da temática e da educação ambiental a aspectos políticos. Encontramos unidades de significado 
que fazem referência a uma perspectiva claramente política para a temática ambiental, relacionando-a com os aspectos econômicos, ambientais e sociais. No entanto, podemos considerar que foram poucos os projetos que trataram da questão política (20 entre 79). Por outro lado, quando consideramos os projetos da Regiāo Norte, entendemos como expressivos os resultados encontrados: dos 20 projetos que trataram da questão política relacionada à questão ambiental, 14 eram da Região Norte do País, seguida da Região Nordeste (3), Sul (2) e Centro-Oeste (1).

Para Carvalho (2006, p. 36), "[...] a dimensão política da educaçáo se caracteriza pela práxis humana, por meio da participação coletiva dos indivíduos na construção do ideal de cidadania e de uma sociedade democrática”. Dessa maneira, entendendo que o potencial transformador da educação só se concretiza na participaçáo efetiva dos indivíduos nos processos de transformaçáo social e que essa participação só acontece através de uma prática contextualizada (CARVALHO, 2006), consideramos importantes as discussóes que vêm sendo travadas nos cursos de Pedagogia nesse sentido.

Em relação ao resultado que encontramos aqui, não nos espanta, devido a resultados anteriores, que a Região Norte do País apresente grande frequência e diversidade de unidades de significado relacionadas a essa questão. É interessante constatar que é nos PPPs dos cursos de Pedagogia oferecidos nessa região que se considera, além das disciplinas tradicionais de um curso dessa natureza, a possibilidade de atividades de extensão e grupos de pesquisa, e de contextualização dos trabalhos a partir das realidades locais como atividades de formação dos futuros professores. Os exemplos que seguem explicitam essa possibilidade:

- "Antropologia no quadro das ciências, natureza, cultura. Estudo da Antropologia em meio rural e em especial nas experiências educacionais" (CARVALHO, 1999) - Disciplina de Antropologia do Meio Rural, PPP Pedagogia da Universidade Federal do Pará (UFPA).

- "[...] E um grupo de pesquisa e construçáo de conhecimentos, numa perspectiva interdisciplinar, tendo como eixo a educação e a diversidade cultural, e como força motriz, os desafios da Amazônia Legal, articulados ao contexto nacional e internacional, priorizando: formação e práxis do educador; educação e construção de identidades amazônicas; educação, história e sociedade, educação, políticas 
públicas e desenvolvimento regional; apropriação ambiental, fauna, flora e recursos hídricos, bem como questóes referentes ao patrimônio histórico, cultural e ambiental. Seu objetivo é discutir de modo interdisciplinar questôes que envolvam: os aspectos históricos, sociais, culturais e ambientais na formação das sociedades e as mediaçóes da educação neste processo [...]" (COMISSÃO, 2007b, p. 79) - PPP Pedagogia da UFT, campus Palmas.

Foram nesses projetos da Regiāo Norte que também encontramos uma abordagem mais politizada no tratamento das questóes ambientais e da relação das sociedades com a natureza. Os excertos que seguem nos abrem possibilidades de refletir sobre essa abordagem:

- "Dessa forma, o curso que pretendemos oferecer precisa explicitar claramente seu compromisso com a oferta de conteúdos capazes de gerar conhecimentos teóricos e práticos que conduzam à autonomia dos sujeitos. Precisa levar em conta as condiçóes a que se encontram subordinadas a produçáo e a reproduçáo da vida humana em sociedade e na relaçáo com a natureza" (COMISSÃO, 2007c, p. 25, grifo nosso) - PPP da UFT, campus Tocantinópolis.

" "Assim, reafirma-se que o sentido das açôes humanas, individuais e coletivas remete-se à luta pela emancipação social. Não de uma liberdade negativa, contraposta à natureza e em relaçáo aos outros indivíduos. Mas uma liberdade positiva, pautada na afirmaçáo da vida e da dignidade de todos" (KONZEN, 2007, p. 23) - (PPP da UFT, campus Miracema.

Outro tema que propusemos a partir das unidades de significado e núcleos de sentido construídos por nós, qual seja, Desenvolvimento e natureza: algumas possibilidades, enfatiza perspectivas e propostas que envolvem, de certa forma, possibilidades alternativas que procuram compatibilizar modelos de desenvolvimento e proteçáo ambiental, tais como a ideia de sustentabilidade, de desenvolvimento sustentável (DS) e de preservação ambiental para a manutenção da vida e bem-estar humano. Fica bastante evidente em nossa análise, por meio das unidades de significado identificadas, o quanto questôes relacionadas ao contexto de DS e de sustentabilidade estáo presentes nos PPPs.

As unidades de significado identificadas no texto e que estâo relacionadas a modelos de desenvolvimento e proteção ambiental levam em conta propostas 
de natureza diversa e foram agrupadas nos seguintes núcleos de sentido: Aproximaçóes com ideias de sustentabilidade e desenvolvimento sustentável; Ideias de preservação ambiental e educação para a preservação ambiental.

Fizeram referência a esses conceitos 12 dos 19 projetos na Regiáo Norte, nove dos 19 no Nordeste, cinco dos 11 no Centro-Oeste, seis entre 15 no Sudeste e dois entre nove no Sul do País. O núcleo de sentido que se refere à "preservação ambiental" foi incluído nesse tema, porque entendemos que, assim como as propostas de sustentabilidade e DS, claro que considerando as grandes diferenças de conotaçóes entre elas, as ideias de preservação ambiental se mostram como uma proposta de manutençáo do meio ambiente ou da natureza em contraposição a padrōes atuais de relação entre as sociedades e a natureza. Assim, 13 projetos apontaram propostas de preservação ambiental (quatro no Norte, três no Centro-Oeste, quatro no Nordeste e dois no Sudeste). Ao longo deste texto, indicaremos mais detalhadamente os projetos que apontaram essas distintas propostas. Ao todo, 48 projetos incorporam nas suas propostas consideraçóes que se relacionam a esse tema.

A ideia de possibilidades alternativas de organização das sociedades vem sendo cogitada por muitos autores que refletem sobre a temática ambiental como um caminho de superação da crise ambiental em que nos encontramos. Já nas primeiras conferências que foram organizadas para a discussão de temas relacionados à degradação ambiental, estavam em pauta aspectos relacionados à organização das sociedades e seus impactos ambientais. Indicava-se a necessidade de construção de alternativas ao desenvolvimento que promove a degradação ambiental. Essas alternativas nem sempre caminhavam para a busca de uma transformaçáo do modelo capitalista de desenvolvimento e muitas vezes apontavam ações paliativas que, de certa forma, reforçavam e reforçam os modelos vigentes e a manutenção do sistema. Com base nessas ideias iniciais, surgiram posteriormente, na década de 1980, as primeiras indicações de um possível "desenvolvimento sustentável". A concepçâo de DS vem sendo amplamente criticada pelo movimento ambientalista. Layrargues (2000, p. 1) afirma que esse conceito se situa no campo da mudança de comportamentos e está associado "[...] à conversão tecnológica na direção da eco-eficiência". Para Lima (2009), tal conceito faz parte do conjunto de ideias neoliberais promovidas para reestruturar o capitalismo, que em meados da década de 1970, no pósGuerra Fria, estava desestabilizado ideologicamente, devido ao abalo das suas prerrogativas de bem-estar social e econômico, e de desenvolvimento e progresso 
para todos. Aliado ao crescimento de evidências e de críticas sobre a poluição gerada pelo sistema capitalista, o conceito ganha força nos documentos oficiais e sugere um contínuo progresso econômico, evitando os problemas ambientais recorrentes.

Uma alternativa a esse modelo é a noção de "sociedades sustentáveis", proposta por ambientalistas para lembrar a impossibilidade de se generalizarem soluções a contextos táo diferenciados e a necessidade de entendimento das múltiplas dimensóes que envolvem projetos de desenvolvimento social (LIMA, 2009). Tal conceito, vinculado ao "Tratado de Educação Ambiental para Sociedades Sustentáveis e Responsabilidade Global", indica uma reorganização econômica pautada pelas diferentes organizaçóes sociais e pelo entendimento de que não há um único desenvolvimento comum a todas as comunidades.

Assim, olhando para os projetos dos cursos de Pedagogia, identificamos muitas passagens que revelam os conceitos de DS e sustentabilidade. Sabendo das diferenças de intenções na utilização de tais conceitos, procuramos identificar aqueles que nos remetem para perspectivas próprias de sociedades sustentáveis e aqueles que enfatizavam nos seus textos o tema do DS. Percebemos, então, que em todos os projetos das Regióes Nordeste e Sudeste os discursos se misturavam, e muitas vezes as duas ideias apareciam em um mesmo projeto, não sendo possível identificar um posicionamento em relação a essa questão. Dessa forma, temos em um mesmo projeto:

" "Capacidade para estabelecer a mediação da produção de referenciais ambientais e habilidades [...] centrada na noção de desenvolvimento sustentável” (MENDONÇA; MELO, s/d, p. 4) - PPP da UFSCar, campus Sorocaba.

E:

" "A dimensão socioambiental da educação com vistas à sustentabilidade" (MENDONÇA; MELO, s/d, p. 4) - Disciplina de EA, Educação, Sociedade e Meio Ambiente da UFSCar, campus Sorocaba.

Dos cinco projetos da Região Centro-Oeste somente dois falavam apenas em sustentabilidade; os outros três misturavam o discurso com os dois conceitos. $\mathrm{Na}$ Regiăo Norte, o termo "desenvolvimento sustentável" é recorrente em muitos dos projetos incluídos nesse tema, ao passo que as ideias de "sociedades sustentáveis" e "sustentabilidade" são pouco presentes (2). Assim, temos: 
" "Compreender os caminhos para o desenvolvimento sustentável" (COMISSÃO, 2007c) - Disciplina de Educação Ambiental, da UFT, campus Tocantinópolis.

" "[...] O papel da educação frente aos problemas regionais e suas contribuiçōes ao desenvolvimento sustentável [...]" (CARVALHO, 1999) - Disciplina de Educação e Problemas Regionais da UFPA.

Ainda considerando os modelos da sustentabilidade e do DS, procuramos perceber aqueles projetos que, de alguma forma, "endereçavam" (CARVALHO, 2004), quando falavam da temática ambiental, à educação para o DS ou para outros fins.

A discussão sobre DS e sustentabilidade caminha junto àquela relacionada a uma possível educação para esses fins. Jickling (1992, apud SAUVÉ, 1999, p. 3 , tradução dos autores) argumenta que "[...] a educação deve permitir que os indivíduos pensem por si. A educação 'para' o DS ou a educação 'para' qualquer coisa é inconsistente nos seus critérios". Nesse sentido, uma proposta da Unesco de substituir a Educação Ambiental por Educação para o DS, no início dos anos 2000, causou bastante controvérsia. Para González-Gaudiano (2007), essa proposta apresenta uma tendência de ascensão linear em cumplicidade com o desenvolvimento do sistema econômico atual e orientada para ele. Tal conceituação permite incluir a ideia de que a Educação Ambiental, - evoluindo - em direção a uma educação para o desenvolvimento sustentável, serviria como ferramenta perfeita do próprio sistema e poderia ser utilizada para sanar o mal que ele mesmo produz: a degradação ambiental e suas implicaçóes. González-Gaudiano afirma ainda que tal programa sugere, implicitamente, que o modelo de desenvolvimento elaborado pelos países desenvolvidos deve ser exemplo para os outros em desenvolvimento, e que a educação que se propóe, vestida com uma ideia de busca de transformação social, coloca como elemento principal a educação escolar normativa, reprodutora, subordinada e instrumental, deixando de lado uma estratégia político-pedagógica mais ampla e crítica. Lima (2009) também se posiciona contra essa mudança e argumenta que ela levaria a uma desconstrução de todo um movimento de cunho crítico e emancipatório que vem construindo a EA no Brasil. O autor afirma que essa desconstrução do termo faz parte de um movimento de luta pelo aspecto simbólico do conceito de sustentabilidade, e nesse sentido Sauvé (1999) faz um alerta para o desenvolvimento dessa ideia na formulação de políticas públicas e de formação de profissionais. 
Encontramos essa ideia de endereçamento da educação para o DS ou sustentabilidade em muitos dos projetos analisados. Considerando os 79 PPPs, 26 indicam tal endereçamento, com destaque para os projetos da Região Norte (12 de 19).

Em relação às ideias de "preservação ambiental" incorporadas a esse tema, encontramos em 13 projetos passagens que apontam tal direcionamento. Citamos três delas:

- "Além disso, busca-se difundir a conscientização em relação à preservação do meio em que se vive [...] dos recursos materiais, naturais e humanos" (FACULDADE, 2009, p. 23) - PPP Pedagogia da Universidade Federal da Grande Dourados(UFGD).

- "Visando atingir os objetivos essenciais de aprimoramento do ensino e estímulo às atividades de pesquisa e de extensão, a UFMS vem participando ativamente da preservação dos recursos naturais do meio ambiente de Mato Grosso do Sul, especialmente da fauna e flora do Pantanal, regiāo onde está inserida" (FUNDAÇÃO, 2007, p. 4) - PPP Pedagogia da Universidade Federal de Mato Grosso do Sul (UFMS), campus Três Lagoas.

- "Analisar o papel da educação ambiental na formaçáo dos sujeitos sociais capaz de conservar a cultura e o ambiente ao qual está inserido" (COMISSÃO, 2007a) - Disciplina de Educação Ambiental, PPP Pedagogia da UFT, campus Arraias.

Essas ideias, que se relacionam pura e simplesmente a noçóes de preservação ambiental, vêm sendo bastante criticadas. Para Jacobi (2005), essa conceituaçáo se vincula à mesma matriz que gerou as ideias de DS, ou seja, uma matriz econômica e técnico-científica que propõe a articulação do crescimento econômico com a preservação ambiental, o que, a nosso ver, parece paradoxal.

Lima (1999) constata que tal concepção reduz a questão ambiental a um “problema estritamente ecológico". Para o autor:

Tal tendência, limitante e enganadora, por um lado, retira da questão ambiental, uma de suas características significativas que é a de unir realidades, articular e relacionar dimensóes complementares que constituem uma complexidade maior. (LIMA, 1999, p. 9). 
Nas sociedades contemporâneas, a crença na natureza como um bem a ser cuidado e preservado, para Carvalho (2001, p. 37), "[...] alimenta a utopia de uma relaçâo simétrica entre os interesses da sociedade e os processos da natureza". Tal ideia nos coloca a refletir se realmente existem possibilidades de uma relação harmoniosa das sociedades com a natureza a partir de um movimento de dicotomização e distanciamento entre elas. O excerto que segue, para nós, reafirma que ideias como essa, de preservação para uma vida em harmonia com a natureza, vêm sendo veiculadas em projetos de cursos de formaçáo de professores como uma opção nas relaçôes dos homens com a natureza.

"A consciência ecológica parte do princípio que o homem é um ser vivo e por isso precisa estar em harmonia [...] com a natureza [...]. Assim, as açôes a serem projetadas para a preservação do verde, da água, da fauna e da flora influenciarão não apenas no humor, mas, especialmente, no contentamento do indivíduo com o mundo, e no nível de felicidade de todos." (COMISSÃO, 2007a, p. 9).

\section{Considerações finais}

De uma maneira geral, consideramos bastante significativas as evidências que encontramos de incorporação da dimensão ambiental nos projetos políticopedagógicos dos cursos de Pedagogia. Trata-se de passagens que evidenciam a presença cada vez mais marcante de discussóes em torno das questóes ambientais na sociedade, a ponto de influenciar propostas curriculares.

Em relação às dimensóes que Carvalho (2006) considera pertinentes para trabalhos relacionados à EA, percebemos que em alguns dos PPPs dos cursos em questáo essas dimensôes têm sido propostas. Contudo, na maioria das vezes, essas proposiçôes carecem de uma fundamentação mais articulada que inclua as diferentes dimensões.

Em relação à dimensão dos conhecimentos, na maioria das vezes, estes estavam vinculados aos conhecimentos acadêmicos, e os poucos projetos que se referiam a uma proposta mais crítica, propondo a integração de outros saberes aos eruditos, eram majoritariamente da regiáo amazônica. A questáo valorativa apareceu bastante nos projetos, porém, as passagens indicavam, muitas vezes, um "respeito ambiental ecológico", termo que não raro se mostrou de difícil 
compreensão. Outro aspecto que nos parece interessante de ser explorado é a abordagem política em relação à temática ambiental. Percebemos, com maior clareza nos projetos da região amazônica, um viés bastante crítico na abordagem da temática ambiental, que, de uma maneira geral, aparecia associada às condiçóes econômicas e sociais. Algumas propostas de atividades mais politizadas, que indicavam a contextualizaçấo com a realidade socioambiental da regiâo, se fizeram presentes de forma diferenciada nos projetos da região amazônica.

No tocante à questão dos possíveis modelos de desenvolvimento e suas relaçóes com a natureza, nos pareceu, principalmente nos projetos da região amazônica, que o termo "desenvolvimento sustentável" é o mais utilizado. Porém, em projetos com perspectivas mais críticas sobre a questão ambiental, não nos pareceu que estivesse sendo enfatizada uma concepção desenvolvimentista em relação a possibilidades alternativas de organização social. O que nos parece é que talvez os termos venham sendo usados sem um embasamento maior sobre suas origens e suas conotaçóes. É interessante observar que, muitas vezes, esses projetos apresentam conceitos de desenvolvimento sustentável e sociedades sustentáveis em um mesmo texto, não indicando um posicionamento claro perante os diferentes termos e reais significados. As ideias de preservação ambiental para a manutenção do bem-estar humano nos pareceram também bastante recorrentes.

Acreditamos que essas tentativas podem significar o primeiro passo para futuras abordagens mais críticas e participativas. Conseguimos vislumbrar tendências que apontam a construção de espaços de discussão de temas relevantes para a EA, porém, em alguns momentos sentimos que essas discussões poderiam estar mais fundamentadas e articuladas, explicitando de forma mais clara pontos de vistas e posicionamentos que implicam perspectivas teóricometodológicas muitas vezes conflitantes.

A partir dessas constataçóes, o que nos parece mais claro é que as ideias que emergem dos PPPs podem significar apenas reflexos de um processo histórico relacionado à introdução da dimensão ambiental nas diferentes esferas sociais, entre elas as formativas. Essas questóes parecem ser ressignificadas em relação a contextos particulares, podendo sofrer, em maior ou menor escala, influências desses diferentes contextos, a depender dos campos de tensóes e disputas envolvidos em cada realidade. Talvez não seja por acaso que, nas Regiōes Sul e Sudeste, tenhamos encontrado menos unidades de significado nos projetos em 
comparação com a região amazônica. Talvez os apelos midiáticos relacionados com as questôes ambientais da região amazônica não sejam acompanhados nas outras regiôes por um tema ambiental que cumpra um papel tâo catalisador quanto o da Floresta Amazônica, por exemplo, e que sensibilize os elaboradores dos PPPs para incluí-lo nestes.

Sendo assim, fica claro que há muito a se discutir ainda sobre a ambientalizaçáo dos currículos do Ensino Superior. Os resultados nos permitem considerar a necessidade de mais estudos e fundamentação do campo da EA e ainda maior clareza nas políticas que incentivam a incorporação da temática na universidade. Os problemas e desafios que atravessam a relação entre currículo, Educação Superior e acontecimento ambiental não se resolvem com a simples incorporação de "uma dimensão ambiental" nos currículos de formação profissional, por meio de disciplinas ou outros componentes curriculares isoladamente considerados (FARIAS, 2008). Seguindo as ideias de Farias (2008), o que o acontecimento ambiental suscita, nesse âmbito, é um questionamento profundo tanto dos princípios de produção, estruturação e organização dos atuais sistemas de conhecimento como das lógicas que presidem as práticas curriculares. Esse questionamento não se restringe aos cotidianos práticos escolares, como se fosse uma questão a ser enfrentada no âmbito de cada instituição em particular ou por cada um de seus agentes individualmente, mas abrange os contextos de produçáo da política educacional, que devem se apresentar de forma clara e fundamentada. Mesmo com essas ressalvas, não podemos deixar de considerar positivo o fato de as questóes ambientais estarem mais presentes nos PPPs desses cursos, haja vista a demanda social pela problemática ambiental e a importância estratégica na sociedade que têm esses profissionais da educação.

\section{REFERÊNCIAS}

ARAÚJO, Ulisses F.; AQUINO, Júlio G. Os direitos humanos na sala de aula: a ética como tema transversal. São Paulo: Moderna, 2001.

ARCE, Alessandra; LUIZ, Maria Cecília (Coord.). Projeto Político Pedagógico do Curso de Licenciatura em Pedagogia. Centro de Educação e Ciências Humanas. UFSCAR, São Carlos, 2008.

BAKHTIN, Mikail. Marxismo e filosofia da linguagem. São Paulo: Hucitec, 1988. 
BARDIN, Laurence. Análise de Conteúdo. Lisboa: Edições 70, 2004.

BONOTTO, Dalva Maria B. Contribuições para o trabalho com valores em Educação Ambiental. Ciência e Educação, Bauru, v. 14, n. 2, p. 295-306, 2008. Disponível em: <http://www.scielo.br/pdf/ciedu/v14n2/a08v14n2. pdf $>$. Acesso em: 5 jul. 2010.

BRASIL. Lei no 9.795, de 27 de abril de 1999. Dispóe sobre a educação ambiental, institui a Política Nacional de Educação Ambiental e dá outras providências. Diário Oficial da União, Brasília, DF, 28 abr. 1999. Disponível em: <http://www.planalto.gov.br/ccivil_03/Leis/L9795.htm>. Acesso em: jan. 2009.

BRASIL. Lei no 10.861, de 14 de abril de 2004. Institui o Sistema Nacional de Avaliação da Educação Superior - SINAES e dá outras. Diário Oficial da União, Brasília, DF, 15 abr. 2004. Disponível em: <http://www.planalto.gov.br/ ccivil_03/_ato2004-2006/2004/lei/l10.861.htm>. Acesso em: 15. dez. 2010.

BRASIL. Conselho Nacional de Educaçãa. Resolução no 1 , de 15 de maio de 2006. Institui Diretrizes Curriculares Nacionais para o Curso de Graduação em Pedagogia, licenciatura. Diário Oficial da União, Brasília, DF, 16 maio 2006. Seção 1, p. 11. Disponível em: <http://portal.mec.gov.br/cne/ arquivos/pdf/rcp01_06.pdf>. Acesso em: 15 jan. 2009.

BRASIL. Ministério da Educação. Secretaria de Educação Fundamental. Parâmetros Curriculares Nacionais: Brasília, DF: MEC/SEF, 1998.

BRASIL. Ministério do Meio Ambiente. Diretoria de Educação Ambiental. Ministério da Educação. Programa Nacional de Educação Ambiental. 3 ed. Brasília, DF: Ministério do Meio Ambiente, 2005.

CARVAlHO, Ana Maria T. (Org.). Proposta de Reestruturação Curricular do Curso de Pedagogia. Universidade Federal do Pará, Belém, 1999.

CARVALHO, Isabel Cristina de Moura. A invenção ecológica: narrativas e trajetórias da Educação Ambiental no Brasil. Porto Alegre: Ed. Universidade/ UFRGS, 2001.

CARVALHO, Isabel Cristina de Moura. Educação Ambiental Crítica: nomes e endereçamentos da educação. In: LAYRARGUES, Philippe Pomier (Coord.). Identidades da Educação Ambiental brasileira. Brasília: Ministério do Meio Ambiente, 2004. p.13-24. 
CARVALHO, Luiz Marcelo de. A temática ambiental e o processo educativo: dimensões e abordagens. In: CINQUETTI, Heloísa Chalmers S.; LOGAREZZI, Amadeu (Org.). Consumo e resíduo: fundamentos para o trabalho educativo. São Carlos: EdUFScar, 2006. p. 19-41.

COMISSÃO de Elaboração do Projeto Político Pedagógico. Projeto Político Pedagógico do Curso de Pedagogia. Campus Arraias. Universidade Federal de Tocantins, UFT, Arraias, 2007a.

COMISSÃO de Elaboração do Projeto Político Pedagógico. Projeto Político Pedagógico do Curso de Pedagogia do Campus de Palmas. Universidade Federal do Tocantins, UFT. Palmas, 2007b.

COMISSÃO de Elaboração do Projeto Político Pedagógico. Projeto Político Pedagógico do Curso de Pedagogia do Campus de Tocantinópolis. Universidade Federal do Tocantins, UFT. Tocantinópolis, 2007c.

COORDENAÇÃO do Curso de Pedagogia. Projeto Politico Pedagógico. Faculdade de Educação. Universidade Federal do Amazonas, UFAM. Manaus, 2009.

CUNHA, Maria C.; BORDAS, Miguel A. Projeto Político Pedagógico do Curso de Pedagogia. Universidade Federal da Bahia, Salvador, s/d.

DEPARTAMENTO de Educação. Projeto Politico Pedagógico de Pedagogia. Campus Rolim de Moura. Universidade Federal de Rondônia, UNIR, Rolim de Moura, 2008.

FACULDADE de Educação. Projeto Político Pedagógico do curso de Licenciatura da Universidade Federal de Grandes Dourados. Universidade Federal de Grandes Dourados, Dourados, 2009.

FARIAS, Carmem Roselaine O. A produção da política curricular nacional para a Educação Superior diante do acontecimento ambiental: problematizaçôes e desafios. 2008. 215 f. Tese (Doutorado em Educação) Universidade Federal de São Carlos, São Carlos, 2008.

FELICIO, Helena Maria S.; SOUZA, Ana Cristina G., SILVA, Fábio B.; BAZON, Fernanda V.; FRANCO, Michelle F. Projeto Pedagógico do Curso de Pedagogia. Universidade Federal de Alfenas, Alfenas, Minas Gerais, 2008. 
FREITAS, Marcos Cezar; GIGLIO, Celia Maria B.; Projeto Pedagógico do Curso de Pedagogia. Escola de Filosofia, Letras e Ciências Humanas. Universidade Federal de São Paulo, São Paulo, 2010.

FREITAS, Maria Teresa A. A abordagem sócio-histórica como orientadora da pesquisa qualitativa. Cadernos de Pesquisa, São Paulo, n. 116, p. 21-39, jul. 2002. Disponível em: <http://www.scielo.br/pdf/cp/n116/14397.pdf>. Acesso em: dez. 2010.

FUNDAÇÃO Universidade Federal do Mato Grosso do Sul. Projeto Político Pedagógico do Curso de Licenciatura e Pedagogia. Campus Três Lagoas, Três Lagoas, 2007.

GOMES, Romeu; NASCIMENTO, Elaine Ferreira. A produção do conhecimento da saúde pública sobre a relação homem-saúde: uma revisão bibliográfica. Cadernos de Saúde Pública, Rio de Janeiro, v. 22, n. 5, p. 901911, maio 2006. Disponível em: <http://www.scielo.br/pdf/csp/v22n5/03. pdf>. Acesso em: jul. 2010.

GONZALEZ, Luciana Thais Villa. A temática ambiental e os cursos superiores de Turismo do Estado de São Paulo. 2008. 120 f. Dissertação (Mestrado em Educação) - Universidade Estadual Paulista Júlio de Mesquita Filho, Rio Claro, 2008.

GONZÁLEZ-GAUDIANO, Edgard. La Educación Ambiental de cara a la problemática global. Ciência UANL (Universidad Autónoma de Nuevo Léon), México, v. X, n. 4, oct./dic. 2007. Disponível em: <http://eprints. uanl.mx/482/1/Problematicaambiental.pdf>. Acesso em: jan. 2009.

JACOBI, Pedro. Educação Ambiental: o desafio da construção de um pensamento crítico, complexo e reflexivo. Educação e Pesquisa, São Paulo, v. 31, n. 2, p. 233-250, maio/ago. 2005. Disponível em: <http://www.scielo. br/pdf/ep/v31n2/a07v31n2.pdf>. Acesso em: 13 ago. 2010.

JUNYENT, Mercé; GELI, Anna Maria; ARBAT, Eva. Características de la ambientalización curricular: modelo aces. In: JUNYENT, Mercé; GELI, Anna Maria; ARBAT, Eva (Ed.). Ambientalización curricular de los estudios superiores. Girona: Universidad de Girona, 2003. p. 15-32.

KONZEN, José O. et al. Projeto Politico Pedagógico do Curso de Pedagogia do Campus de Miracema. Universidade Federal do Tocantins, UFT. Tocantins, 2007. 
LAYRARGUES, Philippe Pomier. Educação para a gestão ambiental. In: LOUREIRO, Carlos Frederico (Org.). Sociedade e meio ambiente: a Educação Ambiental em debate. São Paulo: Cortez, 2000. p. 87-155.

LEFF, Enrique. Epistemologia ambiental. São Paulo: Cortez, 2002.

LIMA, Gustavo Ferreira C. Questão ambiental e educação: contribuições para o debate. Ambiente \& Sociedade, Campinas, ano II, n. 5, p. 135-153, jul./dez. 1999. Disponível em: <http://www.scielo.br/scielo.php?pid=S1414753X1999000200010\&script=sci_arttext>. Acesso em: 23 ago. 2010.

LIMA, Gustavo Ferreira C. Educação Ambiental Crítica: do socioambientalismo às sociedades sustentáveis. Educação e Pesquisa, São Paulo, v. 35, n. 1, p. 145-163, jan./abr. 2009. Disponível em: <http://www. scielo.br/scielo.php?pid=S1517-97022009000100010\&script $=$ sci_arttext $>$. Acesso em: 29 ago. 2010.

MENDONÇA, Viviane M.; MELO, Teresa Mary P.C. Projeto Pedagógico do curso de Licenciatura em Pedagogia do Campus de Sorocaba. Universidade Federal de São Carlos, Sorocaba, s/d.

MOREIRA, Antônio Flávio B.; MACEDO, Elizabeth F. Currículo, identidade e diferença. In: MOREIRA, Antônio Flávio B.; MACEDO, Elizabeth F. (Org.). Currículo, práticas pedagógicas e identidades. Porto: Porto, 2002. p. 11-33.

PAVESI, Alessandra. A ambientalização da formação do arquiteto: o caso do curso de Arquitetura e Urbanismo da Escola de Engenharia de São Carlos (CAU, Eescusp). 2007. 199 f. Tese (Doutorado em Educaçấo) Universidade Federal de São Carlos, São Carlos, 2007.

REDE UNIVERSITÁRIA DE PROGRAMAS DE EDUCAÇÃO AMBIENTAL (RUPEA). Mapeamento da Educação Ambiental em instituiçōes brasileiras de Educação Superior: elementos para discussão de políticas públicas. 2005. 1 CD-ROM.

ROSALEM, Bruna Monize; BAROLLI, Elisabeth. A ambientalização curricular na formaçáo inicial de professores: o curso de Pedagogia da FE - Unicamp. In: ENCONTRO DE PESQUISA EM ENSINO DE CIÊNCIAS. 7., 2009. Florianópolis. Anais... Florianópolis: 2009. 1 CD-ROM.

SAUVÉ, Lucie. La educación ambiental entre la modernidad y la posmodernidad: en busca de un marco educativo integrador. Tópicos en Educación Ambiental, México, v. 1, n. 2, p. 7-27, 1999. 
Los proyectos político pedagógicos de los cursos de pedagogía y los temas ambientales: el caso de las Universidades Federales Brasileñas

\section{Resumen}

La discusión alrededor de la temática ambiental y de las posibilidades y límites del proceso educativo relacionado a las cuestiones propuestas por esta temática se hace presente en muchos sectores de la sociedad actual. La producción y puesta en circulación de investigaciones y la proposición de programas y acciones relacionadas principalmente a la inserción de la educación ambiental en la enseñanza tradicional nos permiten vislumbrar la amplitud que tal iniciativa ha venido tomando. Delante de este contexto, desarrollamos una investigación a nivel de maestría que busca analizar posibles procesos de ambientalización curricular expresos en los proyectos político-pedagógicos (PPP) de los cursos de licenciatura en Pedagogía de las universidades federales brasileñas. De ese modo, el texto que aquí presentamos es un recorte de esta investigación que se desarrolló en el ámbito del Proyecto Observatorio de la Educación CAPES/ INEP/SECADI, en el cual buscamos explicitar los temas ambientales que se hacen presentes en estos proyectos, yendo más a fondo, para este trabajo, en dos de ellos: "Las dimensiones de EA" y "Desarrollo y naturaleza: algunas
Political and educational projects in teacher education courses and environmental topics: the case of Brazilian Federal Universities

\begin{abstract}
Discussions about the environment and the possibilities and limits of the educational process in relation to environmental issues are evident in many social sectors. The development and promotion of studies, and the proposal of programs and actions related to the inclusion of environmental education in formal teaching indicate the range that this proposal has been gaining. In this regard, under the scope of the Educational Observatory Project CAPES/INEP/ SECADI, we conducted research for a master's degree that examined possible “curriculum greening" processes present in pedagogical policy projects (PPPs) for teacher education courses in Brazilian federal universities. The text presented here is a summary of this survey and details two environmental topics found in these projects: "Dimensions of EA" and "Development and Nature: some possibilities." Based on documentary research and with the theoretical support of authors who have attempted to reflect on the meanings of environmental topics for contemporary societies and on critical proposals for environmental education, we explored the meanings attributed to these curriculum greening processes by analyzing the PPPs. We used
\end{abstract}


posibilidades". De ese modo, partiendo de una investigación documental y con el apoyo teórico de autores que han buscado reflexionar sobre los significados de la temática ambiental para las sociedades contemporáneas y sobre propuestas críticas para la Educación Ambiental, buscamos explorar posibles sentidos atribuidos a estos procesos de ambientalización curricular, a partir del análisis de los PPP. Como principal referencia metodológica nos apoyamos en la propuesta de "producción de sentidos" presentada por Gomes y Nascimento (2006). Algunas reflexiones sobre los datos nos permiten vislumbrar qué diferentes temas ambientales han estado siendo tenidos en cuenta en los proyectos de estos cursos, poniendo en evidencia movimientos y procesos de ambientalización curricular.

Palabras clave: Educación ambiental. Formación de profesores. Educación universitaria.

\section{Maíra Gesualdo Oliveira}

E-mail: maira_oliva@hotmail.com

Luiz Marcelo de Carvalho

E-mail: 1marcelo@rc.unesp.br the "production of meanings" proposal by Gomes and Nascimento (2006) as our key methodological reference. Several reflections on this data lead us to conclude that a number of environmental topics have been considered in these courses, which reveals curriculum greening movements and processes.

Keywords: Environmental education. Teacher training. Higher Education. 